\section{JURNAL EKONOMI EFEKTIF}

ISSN : $2622-8882$, E-ISSN : 2622-9935

Jurnal Ekonomi Efektif, Vol. 3, No. 4, Juli 2021

@Prodi Manajemen Fakultas Ekonomi Universitas

Pamulang

\title{
KONTRIBUSI GAYA KEPEMIMPINAN DAN MOTIVASI TERHADAP KINERJA PEGAWAI PADA BADAN KEPEGAWAIAN DAN PENGEMBANGAN SUMBER DAYA MANUSIA KOTA BAUBAU
}

\author{
Ahmad Jamil \\ Universitas Muhammadiyah Sorong, Sorong, Papua Barat, Indonesia \\ jamilscout@gmail.com
}

Manuskrip: Mei -2021 Ditinjau: Mei -2021; Diterima: Mei-2021; Online: Juli-2021; Diterbitkan: Juli-2021

\begin{abstract}
ABSTRAK
Penelitian ini bertujuan untuk mengetahui apakah terdapat hubungan antara gaya kepemimpinan dan motivasi terhadap kinerja pegawai. Penelitian ini dilakukan pada Badan Kepegawaian dan Pengembangan Sumber Daya Manusia kota Baubau dengan menggunakan 38 orang pegawai sebagai sampel. Metode yang digunakan pada penelitian ini adalah kuantitatif dengan pendekatan regresi sederhana untuk membuktikan hipotesis satu dan dua, serta pendekatan analisis jalur (path analysis) untuk membuktikan hipotesis tiga. Hasil analisis membuktikan bahwa terdapat hubungan yang signifikan antara gaya kepemimpinan terhadap kinerja pegawai dengan koefisien pengaruh sebesar 2.595; terdapat hubungan yang signifikan antara motivasi terhadap kinerja pegawai dengan koefisien pengaruh sebesar 4.469; dan terdapat hubungan yang signifikan antara kepemimpinan melalui motivasi terhadap kinerja pegawai dengan koefisien pengaruh sebesar 0.271 atau $27.1 \%$.
\end{abstract}

\section{Kata Kunci: Gaya Kepemimpinan, Motivasi, Kinerja Pegawai}

\section{ABSTRACT}

This study aims to determine whether there is a relationship between leadership style and motivation on employee performance. This research was conducted at the Personnel and Human Resources Development Agency of the city of Baubau using 38 employees as a sample. The method used in this research is quantitative with a simple regression approach to prove hypotheses one and two, and a path analysis approach to prove hypothesis three. The results of the analysis prove that there is a significant relationship between leadership style and employee performance with an influence coefficient of 2,595; there is a significant relationship between motivation on employee performance with an influence coefficient of 4.469; and there is a significant relationship between leadership through motivation on employee performance with an influence coefficient of 0.271 or $27.1 \%$.

Keywords: Leadership Style, Motivation, Employee Performance 


\section{PENDAHULUAN}

\section{A. Latar Belakang}

Keberhasilan suatu organisasi dalam mencapai tujuannya sangat ditentukan oleh kinerja pegawainya, sebab kinerja pegawai merupakan landasan sesungguhnya sebuah organisasi. Apabila kinerja pegawai baik maka organisasipun akan baik baik saja. Dan jika kinerja pegawainya tidak baik, maka organisasipun akan berada dalam masalah. Handoko (2008:75) menjelaskan bahwa kinerja pegawai pada dasarnya adalah gambaran mengenai kemampuan pegawai dalam menangani setiap pekerjaan, tinggi rendahnya kinerja pegawai dapat dinilai oleh kemampuan pegawai dalam menghasilkan suatu pekerjaan yang sesuai dengan standar yang telah ditetapkan.

Mengetahui kinerja pegawai sangatlah perlu bagi organisasi, sebab dengan demikian maka organisasi akan mampu mengukur sejauh mana organisasi dapat bekerja untuk mencapai tujuanya. Organisasi juga dapat menilai apakah pegawai mampu dalam melaksanakan tugasnya dan telah mencapai hasil yang ditetapkan atau tidak. Dengan begitu, organisasi akan mampu mengevaluasi dan membuat perencanaan selanjutnya.

Pegawai harus dipimpin oleh orang yang mempunyai kualitas dalam memimpin. Kualitas tersebut tercermin jika pemimpin mampu membaca keadaan lingkungan organisasi yang dipimpinnya, mampu memengaruhi dan mengendalikan bawahan dengan berbagai watak dan sifat, serta pemimpin juga mampu untuk mengambil keputusan yang terbaik untuk mencapai tujuan organisasi. Yuniarsih dan Suwatno (2008:165) menyatakan kepemimpinan adalah kemampuan dan kekuatan seseorang untuk mempengaruhi pikiran (mindset) orang lain agar mau dan mampu mengikuti kehendaknya, dan memberi inspirasi kepada pihak lain untuk merancang sesuatu yang lebih bermakna.

Setiap pemimpin harus mempunyai gaya dalam menjalankan tugasnya. Gaya ini merupakan perilaku dan strategi yang digunakan dalam upaya memengaruhi bawahan. Gaya ini juga yang menjadikan ciri khas dari seorang pemimpin. Gaya ini pun merupakan cara untuk menangani pegawai dengan sifat, watak, karakter dan tujuan yang berbeda beda. Menurut Tjiptono (2006:161), gaya kepemimpinan adalah suatu cara yang digunakan pemimpin dalam berinteraksi dengan bawahannya. Lebih lanjut, Heidjrachman dan Husnan (2002:224) berpendapat bahwa gaya kepemimpinan merupakan pola tingkah laku yang dirancang untuk mengintegrasikan tujuan organisasi dengan tujuan individu untuk mencapai tujuan tertentu.

Selain gaya kepemimpinan, organisasi juga harus mampu dalam memberikan motivasi kepada pegawainya. Motivasi merupakan satu hal penting yang akan membuat pegawai terdorong untuk melakukan sesuatu yang lebih dari sebelumnya. Disamping itu motivasi akan memberikan daya gerak kepada pegawai agar mereka mau bekerja sesuai dengan apa yang ditargetkan (Winardi, 2002:1).

Jika pegawai mendapatkan motivasi, mereka akan melakukan pekerjaanya dengan sebaik - baiknya. Mereka akan menetukan pilihan - pilihan positif terhadap berbagai pilihan yang ada di depanya. Akan memacu mereka untuk bekerja lebih keras dan bekerja ikhlas dengan mengeluarkan seluruh energi yang ada pada dirinya demi mencapai tujuan organisasi yang telah di tetapkan. Hal ini senada dengan yang dikemukakan Wursanto (2005:132) bahwa motivasi adalah alasan dorongan yang ada dalam diri manusia yang menyebabkan manusia melakukan sesuatu atau berbuat sesuai dengan apa yang diperintahkan.

Proses pemberian motivasi seharusnya tergantung pada apa yang dibutuhkan oleh pegawai. Jika pegawai tersebut merasa sangat membutuhkan sesuatu maka ia akan terdorong untuk bekerja lebih tinggi. Pemberian motivasi dapat berupa gaji, tunjangan, 
kebutuhan akan rasa aman, kebutuhan akan tempat kerja yang nyaman, hubungan personal dan sebagainya.

Pemerintah kota Baubau melalui kebijakan Walikota Baubau telah memberlakukan sistem kerja lima hari dari yang sebelumnya enam hari dalam satu minggu sejak tanggal 1 Januari 2017. Tentu ini akan berdampak pada bertambahnya beban kerja pegawai yang ada di Kota Baubau. Pekerjaan yang biasanya diselesaikan selama enam hari, kini hanya menjadi lima hari. Jika kinerja pegawai hanya seperti hari biasanya, maka dapat menyebabkan kinerja pegawai menjadi buruk, sebab terdapat satu hari pekerjaan yang tidak selesai.

Sejak diberlakukan tanggal 1 januari 2017 hingga dua minggu berjalan, nampaknya semua tidak berjalan sebagaimana mestinya. Masih terdapat kantor dinas pemerintah Kota Baubau yang masih merasa beban kerja mereka menjadi lebih tinggi. Permasalahan beban kerja ini juga dirasakan oleh Badan Kepegawaian dan Pengembangan Sumber Daya Manusia Kota Baubau. Badan Kepegawaian dan Diklat Daerah Kota Baubau yang melayani sekitar 4995 pegawai yang ada di Kota Baubau merasa beban kerja mereka menjadi lebih tinggi. Pegawai harus mampu menyelesaikan pekerjaan lebih cepat dari sebelumnya agar semua berjalan dengan sebagaimana mestinya. Apabila tidak ditangani dengan baik, akan membuat rapor kinerja pemerintah menjadi buruk. Seperti yang terjadi pada tahun 2013, rangking kota Baubau menempati urutan paling bawah yaitu 91 dari yang sebelumnya rangking 53 dalam hal kinerja penyelenggaraan pemerintah daerah yang dikeluarkan oleh Kemendagri. Berikut data evaluasi penetapan peringkat dan status kinerja penyelenggaraan pemerintahan daerah yang dikeluarkan oleh kemendagri mulai tahun 2010 sampai 2014.

Tabel 1. Evaluasi Penetapan Peringkat dan Status Kinerja Penyelenggaraan Pemerintah oleh Kemendagri

\begin{tabular}{|c|c|c|c|}
\hline \multirow{2}{*}{ TAHUN } & \multicolumn{2}{|c|}{ PERINGKAT } & \multirow{2}{*}{ STATUS } \\
\cline { 2 - 3 } & NOMOR & SKOR & \\
\hline 2010 & 68 & 2.3648 & Tinggi \\
\hline 2011 & 53 & 2.6120 & Tinggi \\
\hline 2012 & 77 & 1.7679 & Sedang \\
\hline 2013 & 91 & 0.8310 & Rendah \\
\hline 2014 & 46 & 2.7738 & Tinggi \\
\hline
\end{tabular}

Oleh karena itu, untuk bisa membuat kinerja pegawai menjadi lancar, dibutuhkan pemimpin yang mampu mengkoordinasikan semua hal dan memotivasi pegawai sehingga pegawai mampu bekerja lebih dari sebelumnya.

\section{B. Rumusan Masalah}

1. Apakah Gaya Kepemimpinan berkontribusi terhadap Kinerja Pegawai pada Badan Kepegawaian dan Pengembangan SDM Kota Baubau

2. Apakah Motivasi berkontribusi terhadap Kinerja Pegawai pada Badan Kepegawaian dan Pengembangan SDM Kota Baubau

3. Apakah Gaya Kepemimpinan berkontribusi tidak langsung terhadap Kinerja Pegawai melalui Motivasi pada Badan Kepegawaian dan Pengembangan SDM Kota Baubau

\section{Tujuan Penelitian}

Adapun tujuan penelitian ini adalah:

1. Menganalisis kontribusi gaya kepemimpinan terhadap kinerja pegawai pada Badan Kepegawaian dan Pengembangan Sumber Daya Manusia Kota Baubau.

2. Menganalisis kontribusi motivasi terhadap kinerja pegawai pada Badan Kepegawaian dan Pengembangan Sumber Daya Manusia Kota Baubau 
3. Mengetahui gaya kepemimpinan memiliki kontribusi tidak langsung terhadap kinerja melalui motivasi pada Badan Kepegawaian dan Pengembangan Sumber Daya Manusia Kota Baubau

\section{METODE PENELITIAN}

\section{Populasi}

Populasi dalam penelitian ini adalah seluruh pegawai yang berada di Badan Kepegawaian dan Pengembangan Sumber Daya Manusia Kota Baubau yang berjumlah 38 orang.

2. Sampel

Sampel pada penelitian ini adalah pegawai Badan Kepegawaian dan Pengembangan Sumber Daya Manusia Kota Baubau yang berjumlah 38 orang.

\section{Jenis Penelitian}

Dalam penelitian ini menggunakan jenis penelitian kuantiatif yang bertujuan untuk mengembangkan model matematik yang dalam pengambilan kesimpulan tidak hanya dari kajian literatur atau teori tetapi juga melihat hubungan antara pengamatan dan data secara kuantiatif

\section{Metode Analisis Data}
a. Analisis Deskriptif
b. Analisis Jalur (Path Analysis)
c. Pengujian Hipotesis secara parsial (Uji t)
d. Uji hipotesis secara simultan (Uji F )
e. Koeefisien Determinasi (R2)

\section{HASIL PENELITIAN DAN PEMBAHASAN}

\section{Uji Validitas}

Tabel 2. Uji Validitas Gaya Kepemimpinan

\begin{tabular}{|c|c|c|}
\hline Pernyataan & Korelasi & Keterangan \\
\hline 1 & .596 & r hitung $>0,30$ (valid) \\
\hline 2 & .776 & r hitung $>0,30$ (valid) \\
\hline 3 & .814 & r hitung $>0,30$ (valid) \\
\hline 4 & .586 & r hitung $>0,30$ (valid) \\
\hline 5 & .791 & r hitung $>0,30$ (valid) \\
\hline 6 & .755 & r hitung $>0,30$ (valid) \\
\hline 7 & .589 & r hitung $>0,30$ (valid) \\
\hline
\end{tabular}

Berdasarkan tabel 2 uji validitas untuk variabel gaya kepemimpinan nilai $r$ hitung $>0,30$. Pernyataan yang terdiri atas 7 item pada variabel gaya kepemimpinan dinyatakan valid dan dapat diikutkan pada uji reliabilitas.

Tabel 3. Uji Validitas Motivasi

\begin{tabular}{|c|c|c|}
\hline Pernyataan & Korelasi & Keterangan \\
\hline 1 & .349 & r hitung $>0,30$ (valid) \\
\hline 2 & .581 & r hitung $>0,30$ (valid) \\
\hline 3 & .523 & r hitung $>0,30$ (valid) \\
\hline 4 & .684 & r hitung $>0,30$ (valid) \\
\hline 5 & .683 & r hitung $>0,30$ (valid) \\
\hline 6 & .701 & r hitung $>0,30$ (valid) \\
\hline 7 & .511 & r hitung $>0,30$ (valid) \\
\hline 8 & .684 & r hitung $>0,30$ (valid) \\
\hline 9 & .597 & r hitung $>0,30$ (valid) \\
\hline 10 & .778 & r hitung $>0,30$ (valid) \\
\hline 11 & .660 & r hitung $>0,30$ (valid) \\
\hline 12 & .745 & r hitung $>0,30$ (valid) \\
\hline
\end{tabular}


Untuk uji validitas yang ditunjukan pada tabel 3 dengan variabel motivasi yang terdiri dari 12 item dinyatakan valid dan dapat diikutkan dalam uji reliabilitas. Hal ini dibuktikan dengan nilai $r$ hitung $>0,30$.

Tabel 4. Uji Validitas Kinerja

\begin{tabular}{|c|c|c|}
\hline Pernyataan & Korelasi & Keterangan \\
\hline 1 & .655 & $\mathrm{r}$ hitung $>0,30$ (valid) \\
\hline 2 & .708 & $\mathrm{r}$ hitung $>0,30$ (valid) \\
\hline 3 & .801 & $\mathrm{r}$ hitung $>0,30$ (valid) \\
\hline 4 & .763 & $\mathrm{r}$ hitung $>0,30$ (valid) \\
\hline 5 & .782 & $\mathrm{r}$ hitung $>0,30$ (valid) \\
\hline
\end{tabular}

Berdasarkan tabel 4 pada variabel kinerja memiliki nilai $r$ hitung $>0,30$, maka $r$ hitung pada tabel 4 semua instrumen yang digunakan valid dan dapat diikutkan dalam uji reliabilitas.

\section{Uji Reliabilitas}

Dalam pembahasan ini adalah hasil uji reliabilitas instrumen dengan pengolahan data menggunakan SPSS

Tabel 5. Uji Reliabilitas

\begin{tabular}{|c|c|c|c|}
\hline Variabel & Jumlah Pertanyaan & $\begin{array}{c}\text { Koefisien } \\
\text { Reliabilitas }\end{array}$ & Keterangan \\
\hline $\mathrm{X} 1$ = Gaya Kepemimpinan & 7 & 0.829 & Reliabel \\
\hline Y1 = Motivasi & 12 & 0.852 & Reliabel \\
\hline Y2 = Kinerja & 5 & 0.794 & Reliabel \\
\hline
\end{tabular}

Berdasarkan tabel 5, nilai cronbach's alpha setiap variabel menunjukan intrumen yang digunakan reliabel atau memberikan hasil yang relatif konstan jika dihitung berulang - ulang. Hal ini ditunjukan dengan hasil dengan hasil koefisien reliabilitas > $\alpha 0.60$

\section{Hasil Analisis Jalur (Path Analysis)}

Tabel 6. Ringkasan Estimasi Koefisien Jalur Pengaruh Gaya Kepemimpinan dan Motivasi terhadap Kinerja Pegawai (N=38)

\begin{tabular}{|c|c|c|c|c|}
\hline $\begin{array}{c}\text { Hubungan Kausal } \\
\text { antar Variabel }\end{array}$ & Koefisien Jalur & Standar Error & t-hitung & Hasil Uji \\
\hline X1 ke Y1 & 0.488 & 0.247 & 3.358 & 0.002 \\
\hline X1 ke Y2 & 0.323 & 0.085 & 2.595 & 0.014 \\
\hline Y1 ke Y2 & 0.556 & 0.050 & 4.469 & 0.000 \\
\hline
\end{tabular}

Berdasarkan tabel 6, besarnya kontribusi variabel gaya kepemimpinan (X1) ke motivasi (Y1) adalah 0.488 dengan hasil uji signifikan. Kemudian kontribusi variabel gaya kepemimpinan (X1) ke kinerja (Y2) secara langsung sebesar 0.323 dan mendapatkan hasil uji signifikan. Besarnya kontribusi motivasi (Y1) ke kinerja (Y2) sebesar 0.556 dengan hasil uji signifikan.

Tabel 7. Estimasi Persamaan Struktural Pengaruh Gaya Kepemimpinan dan Motivasi Terhadap Kinerja Pegawai

\begin{tabular}{|c|c|c|}
\hline Model Path & Persamaan Jalur Path & $\mathrm{R}^{2}$ \\
\hline$Y 1=$ pyx $1 X 1+$ pye 2 & $\mathrm{Y} 1=0.488 \mathrm{X} 1+0.762$ & 0.238 \\
\hline$Y 2=$ pyx1X1+ pyy1Y1+pye1 & $\mathrm{Y} 2=0.323 \mathrm{X} 1+0.556 \mathrm{Y} 1+0.436$ & 0.564 \\
\hline
\end{tabular}

Tabel 8. Hasil Pengaruh Langsung dan Tidak Langsung

\begin{tabular}{|c|c|c|}
\hline Pengaruh & $\begin{array}{c}\text { Hubungan Variabel dan } \\
\text { Nilai Koefisien Jalur }\end{array}$ & Total \\
\hline Langsung & X1 ke Y2 & 0.323 \\
& $(0.323)$ & $(32.3 \%)$ \\
\hline Tidak Langsung & X1 ke Y1 x Y1 ke Y2 & 0.271 \\
\hline
\end{tabular}




\begin{tabular}{|c|c|}
\hline$(0,488 \times 0.556)$ & $(27.1 \%)$ \\
\hline Total pengaruh langsung dan tidak langsung & $0.594(59.4 \%)$ \\
\hline Pengaruh variabel $\varepsilon$ terhadap Y2 & $0.40640 .6 \%$ \\
\hline Total & $100 \%$ \\
\hline
\end{tabular}

Berdasarkan tabel 8 hubungan variabel dan nilai koefisien jalur variabel gaya kepemimpinan (X1) terhadap kinerja pegawai (Y2) menunjukan bahwa pengaruh langsung sebesar 0.323 atau sebesar $32.3 \%$, sedangkan pengaruh tidak langsung variabel gaya kepemimpinan (X1) melalui motivasi (Y1) mempengaruhi kinerja (Y2) dihitung dengan mengalikan gaya kepemimpinan (X1) ke motivasi (Y1) dan motivasi (Y1) ke kinerja (Y2): $(0,488 \times 0.556)=0.271(27.1 \%)$.

Masih berdasarkan tabel 8 bahwa nilai total pengaruh variabel gaya kepemimpinan (X1) dan motivasi (Y1) terhadap kinerja pegawai (Y2) sebesar 59.4\% dan $40.6 \%$ yakni pengaruh dari variabel lain $\varepsilon$ terhadap kinerja pegawai (Y2) yang tidak diangkat dalam penelitian ini.

\section{Uji F}

Uji F untuk menghitung koefisien secara keseluruhan (simultan). Kaidah pengujian signfikasi jika nilai probabilitas 0.05 lebih besar atau sama dengan nilai probabilitas Sig atau (0.05 > Sig). Maka Ho ditolak dan H1 diterima, artinya signifikan.

Tabel 9. Perhitungan Uji F Kinerja Pegawai (Y2) sebagai Variabel Dependen

\begin{tabular}{|c|c|c|c|c|c|c|}
\hline \multicolumn{2}{|c|}{ Model } & Sum of Squares & Df & Mean Square & F & Sig. \\
\hline \multirow{3}{*}{1} & Regression & 85.301 & 2 & 42.651 & & \multirow{2}{*}{24.972} \\
\cline { 2 - 5 } & Residual & 59.777 & 35 & 1.708 & \\
\hline & Total & 145.079 & 37 & & & \\
\hline
\end{tabular}

Tabel 9 menunjukan nilai Fhitung $=24.972>$ Ftabel $=3.266$ dengan signifikasi 0.000. Taraf signifikasi tersebut lebih kecil dari 0.05 sehingga dapat disimpulkan bahwa gaya kepemimpinan (X1) dan motivasi (Y1) secara bersama - sama mempengaruhi kinerja pegawai (Y2).

\section{Uji T}

Uji T untuk menghitung koefisien jalur secara individu. Signifikasi analisis jalur dibandingkan dengan nilai probabilitas 0.05 dengan nilai probabilitas Sig dengan dasar pengambilan keputusan jika nilai probabilitas 0.05 lebih besar atau sama dengan nilai probabilitas $(0.05>\mathrm{Sig})$, maka Ho ditolak dan H1 diterima, artinya signifikan.

Tabel 10. Perhitungan Uji T Kinerja (Y2) sebagai Variabel Dependen

\begin{tabular}{|l|l|r|r|r|r|r|}
\hline \multirow{2}{*}{ Model } & \multicolumn{2}{|c|}{$\begin{array}{l}\text { Unstandardized } \\
\text { Coefficients }\end{array}$} & $\begin{array}{l}\text { Standardized } \\
\text { Coefficients }\end{array}$ & \multirow{2}{*}{ T } & Sig. \\
\cline { 3 - 5 } \multicolumn{2}{|c|}{} & \multicolumn{1}{|c|}{ B } & Std. Error & Beta & & \\
\hline & Constant) & 3.100 & 2.639 & & 1.175 & .248 \\
\hline 1 & Kepemipinan (X1) & .222 & .085 & .323 & 2.595 & .014 \\
\hline & Motivasi (Y1) & .225 & .050 & .556 & 4.469 & .000 \\
\hline
\end{tabular}

Berdasarkan tabel 10, terlihat bahwa nilai t hitung $=4.469>$ t tabel $=1.306$ dengan signifikasi 0.000. Taraf signifikasi tersebut lebih kecil dari 0.05 sehingga dapat disimpulkan motivasi berpengaruh positif dan signifikan terhadap kinerja pegawai.

Tabel 11. Perhitungan Uji T Motivasi (Y1) sebagai Variabel Dependen

\begin{tabular}{|l|l|r|r|r|r|r|}
\hline \multirow{2}{*}{ Model } & \multicolumn{2}{|l|}{ Unstandardized Coefficients } & \multicolumn{2}{|l|}{$\begin{array}{l}\text { Standardized } \\
\text { Coefficients }\end{array}$} & \multirow{2}{*}{ T Sig. } \\
\cline { 2 - 5 } \multicolumn{2}{|l|}{} & \multicolumn{2}{|c|}{ B } & Std. Error & Beta & \\
\hline & Constant) & 25.386 & 7.661 & & 3.314 & .002 \\
\hline 1 & Kepemipinan (X1) & .830 & .247 & .488 & 3.358 & .002 \\
\hline
\end{tabular}

Berdasarkan tabel 11 diatas nilai thitung $3.358>$ ttabel $=1.306$ dengan signifikasi 
0.002 yang menunjukan lebih kecil dari standar signifikasi 0.05, maka dapat disimpulkan gaya kepemimpinan berpengaruh positif dan signifikan terhadap motivasi.

\section{Koefisien Determinasi $\left(\mathbf{R}^{2}\right)$}

Tabel 12. Koefisien Determinasi $\left(\mathrm{R}^{2}\right)$ Kinerja Pegawai (Y2) sebagai Variabel Dependen

\begin{tabular}{|c|c|c|c|c|c|c|c|c|c|}
\hline \multirow[b]{2}{*}{$\begin{array}{r}\text { Model } \\
s \\
\end{array}$} & \multirow[b]{2}{*}{$\mathrm{R}$} & \multirow[b]{2}{*}{$\begin{array}{c}\mathrm{R} \\
\text { Squar e }\end{array}$} & \multirow[b]{2}{*}{$\begin{array}{l}\text { Adjuste d } \\
\text { R Square }\end{array}$} & \multirow{2}{*}{$\begin{array}{c}\text { Std. Error } \\
\text { of the } \\
\text { Estimat } \\
\mathrm{e}\end{array}$} & \multicolumn{5}{|c|}{ Change Statistics } \\
\hline & & & & & $\begin{array}{c}\text { R Square } \\
\text { Change }\end{array}$ & $\begin{array}{c}\mathrm{F} \\
\text { Change }\end{array}$ & df1 & df2 & $\begin{array}{c}\text { Sig. F } \\
\text { Change }\end{array}$ \\
\hline 1 & $.767^{\mathrm{a}}$ & .588 & .564 & \begin{tabular}{|c|}
1.3068 \\
8
\end{tabular} & .588 & 24.972 & 2 & 35 & .000 \\
\hline
\end{tabular}

Hasil perhitungan berdasarkan tabel 12 koefisien determinasi pada variabel kinerja sebesar 0.588 , di mana $58.8 \%$ kinerja pegawai dapat dijelaskan oleh gaya kepemimpinan dan motivasi. Sedangkan $41.2 \%$ kinerja pegawai dapat dijelaskan dengan variabel lain yang tidak diangkat dalam penelitian ini.

\section{Pembahasan Hasil Penelitian}

\section{Kontribusi Gaya Kepemimpinan (X1) dan Kinerja Pegawai (Y2)}

Berdasarkan hasil persamaan regresi gaya kepemimpinan terhadap kinerja pegawai menunjukan bahwa nilai thitung $=2.595>\mathrm{t}$ tabel $=1.306$ dengan signifikasi 0.014 lebih kecil dari 0.05 . Sehingga dapat disimpulkan bahwa gaya kepemimpinan berpengaruh positif dan signifikan terhadap kinerja pegawai pegawai pada Badan Kepegawaian dan Pengembangan Sumber Daya Manusia Kota Baubau. Hal ini menunjukan semakin tinggi gaya kepemimpinan maka akan memberikan pengaruh terhadap kinerja pegawai.

\section{Kontribusi Motivasi (Y1) dan Kinerja Pegawai (Y2)}

Berdasarkan hasil regresi yang dilakukan antar motivasi terhdap kinerja pegawai terlihat bahwa nilai thitung $=4.469>$ t tabel $=1.306$ dengan signifikasi 0.000 . Taraf signifikasi tersebut lebih kecil dari 0.05 sehingga dapat disimpulkan motivasi berpengaruh positif dan signifikan terhadap kinerja pegawai pada Badan Kepegawaian dan Pengembangan Sumber Daya Manusia Kota Baubau. Hal ini menunjukan bahwa semakin tinggi motivasi yang diberikan akan memberikan dampak kinerja yang baik pada pegawai.

\section{Kontribusi Gaya Kepemimpinan (X1) dan Motivasi (Y1) secara simultan terhadap (Y2)}

Berdasarkan hasil regresi yang dilakukan menunjukan bahwa nilai Fhitung = $24.972>$ Ftabel $=3.266$ dengan signifikasi 0.000. Taraf signifikasi tersebut lebih kecil dari 0.05 sehingga dapat disimpulkan bahwa gaya kepemimpinan (X1) dan motivasi (Y1) secara bersama - sama mempengaruhi kinerja pegawai (Y2). Berdasarkan hasil penelitian tersebut, bahwa jika secara bersama - sama gaya kepemimpinan dan motivasi akan memberikan pengaruh yang baik terhadap kinerja pegawai.

\section{Kontribusi Gaya Kepemimpinan (X1) melalui Motivasi (Y1) terhadap Kinerja Pegawai (Y2)}

Dari hasil olah data persamaan struktural estimasi pada tabel 4.12 maka diperoleh koefisien jalur X1 ke Y1 = 0.488 dengan hasil uji signifikan. Hal ini berarti bahwa gaya kepemimpinan mempunyai pengaruh yang signifikan terhadap motivasi. Koefisien jalur Y1 ke Y2 $=0.556$ dengan hasil uji signifikan. Hal ini juga berariti bahwa motivasi 
mempunyai pengaruh yang signifikan terhadap kinerja pegawai.

\section{KESIMPULAN DAN SARAN}

\section{Kesimpulan}

Berdasarkan hasil dan pembahasan yang telah dipaparkan pada bab IV, maka dapat ditarik kesimpulan sebagai berikut:

a. Ada pengaruh positif dan signifikan gaya kepemimpinan terhadap kinerja pegawai. Sehingga pada hipotesis pertama yang menyatakan gaya kepemimpinan berpengaruh positif dan signifikan dapat diterima.

b. Ada pengaruh positif dan signifikan motivasi terhadap kinerja pegawai, maka hipotesis ke dua yang mengatakan motivasi memiliki pengaruh yang positif dan signifikan dapat diterima.

c. Terdapat hubungan tidak langsung gaya kepemimpinan terhadap kinerja melalui motivasi. Sehingga hipotesis ke tiga yang menyatakan gaya kepemimpinan memiliki pengaruh tidak langsung terhadap kinerja melalui motivasi.

\section{Saran}

a. Mengingat bahwa motivasi merupakan variabel yang paling dominan berpengaruh terhadap kinerja pegawai, maka disarankan agar mempertahankan atau bahkan meningkatna motivasi yang selama ini telah dijalankan.

b. Disarankan kepada pimpinan agar dalam menjalankan kepemimpinanya disesuaikan dengan kondisi yang ada sehingga peran pemimpin dalam menjalankan organisasi dapat menjadi pemacu kinerja pegawai.

\section{DAFTAR PUSTAKA}

Dianty, M. 2014. Pengaruh Gaya Kepemimpinan Terhahdap Kinerja Karyawan Pada Kantor PT. Jaya Makmur Gemilang Mandiri di Samarinda. Journal Administrasi Bisnis. Vol. 2 No. 2

Fahmi, I. 2011. Manajemen Kinerja Teori dan Aplikasi. Bandung: Alfabeta

Handoko, Hani. 2008. Manajemen Personalia dan Sumber Daya Manusia. BPFE: Yogyakarta Hasibuan, Malayu S.P. 2005. Manajemen Sumber Daya Manusia, Edisi Revisi. Jakarta: Bumi Aksara Heidjrachman dan Husnan. 2002. Manajemen Personalia. Yogyakarta: BPFE UGM

Mangkunegara, P.A.2008. Manajemen Sumber Daya Manusia Perusahaan.Edisi Dari Teori Ke Praktik, Bandung : Alfabeta

Marpaung, M. 2014. Pengaruh Kepemimpinan dan Team Work Terhadap Kinerja Karyawan di Koperasi Sekjen Kemendikbud Senayan Jakarta. Jurnal Ilmiah Widya. Vol. 2 No. 1

Mathis Robert dan Jacson John. 2002. Human Resource Managment. Alih Bahasa. Jakarta: Salemba Empat Nawawi, Hadari. 2003. Manajemen Sumber Daya Manusia Untuk Bisnis yang Kopetitif. Yogyakarta: Gadjah Mada University Press

Meilawati, D., Rawi, R. D. P., Lewenussa, R., \& Bintari, W. C. (2019). Pengaruh Pemberian Insentif Terhadap Kinerja Karyawan Pada Pt Telesindoshop Kota Sorong. Manajemen Dewantara, 3(1), 128-137.

Murty, W.A dan Hudlwinarsih,G.2012. Pengaruh Kompensasi, Motivasi Dan Komitmen Organisasional Terhadap Kinerja Karyawan Bagian Akuntansi. The Indonesian Accounting Review. Vol.2 No.2

Palagia, Brasit dan Amar. 2012. Remunerasi, Motivasi dan Kepuasan Kerja Terhadap Kinerja Pegawai Pada Kantor Pajak. Jurnal Analisis. Vol. 1 No 1 
Pasolong, Harbani. 2013. Kepemimpinan Birokrasi. Bandung . alfabeta

Rawi, R. D. P., \& Kadir, M. A. A. (2018). Analisis Hubungan Motivasi Terhadap Kinerja Pegawai (Studi Kasus Pada Kantor Wali Kota Sorong Papua Barat). Manajemen Dewantara, 2(2), 87-94.

Ridwan dan Kuncoro E.A. 2013. Cara Menggunakan dan Memakai Path Analysis (Analisis Jalur). Bandung: Alfabeta

Robbins, Stephen P. (2006). Perilaku Organisasi. Edisi kesepuluh. Jakarta: PTIndeks Kelompok Gramedia Sanusi, A. 2011. Metodologi Penelitian Bisnis. Jakarta:Salemba empat

Roscahyo, A.2013. Pengaruh Gaya Kepemimpinan Terhadap Kinerja Karyawan Pada Rumah Sakit Siti Khodijah Sidoarjo. Jurnal Ilmu dan Riset Manajemen. Vol.2 No.12

Rozi, A., \& Sunarsi, D. (2020). The Influence of Motivation and Work Experience on Employee Performance at PT. Yamaha Saka Motor in South Tangerang. Jurnal Office, $5(2), 65-74$.

Santoso, A. B., \& Fitriyanti, F. (2020). Pengaruh Kepemimpinan dan Disiplin Kerja Terhadap Kinerja Karyawan Pada Bagian Operasional PT. Bank Central Asia, TBK. Kantor Pusat Jakarta Barat. JENIUS (Jurnal Ilmiah Manajemen Sumber Daya Manusia), 4(1), 33-40.

Sobarna, A., Hambali, S., Sutiswo, S., \& Sunarsi, D. (2020). The influence learning used $\mathrm{ABC}$ run exercise on the sprint capabilities. Jurnal Konseling dan Pendidikan, 8(2), 67-71.

Sudarso, A. P. (2017). Analisis Pengaruh Gaya Kepemimpinan Dan Insentif Terhadap Kinerja Karyawan Pada Yayasan Pendidikan Mulia Buana. JENIUS (Jurnal Ilmiah Manajemen Sumber Daya Manusia), 1(1).

Sugiyono. 2010. Metode Penelitian Kuantitatif Kualitatif \& RND. Bandung: Alfabeta Sugiyono. 2013. Metode Penelitian Pendidikan. Bandung: Alfabeta

Suryani, N. L. (2018). Pengaruh Gaya Kepemimpinan Dan Motivasi Terhadap Kinerja Karyawan Pada PT. Boga Lestari Sentosa (Kenny Rogers Roasters) Indonesia. JENIUS (Jurnal Ilmiah Manajemen Sumber Daya Manusia), 2(1).Rawi, R. D. P. (2017). Analisis Hubungan Motivasi Terhadap Kinerja Pegawai (Studi Kasus Pada Kantor Kecamatan Ruing Kabupaten Ngada Ntt). Jurnal Noken: Ilmu-Ilmu Sosial, 2(2), 15-28.

Sutrisno, E. 2009. Manajemen Sumber Daya Manusia. Jakarta:Kencana

Suwatno dan Priansa, D.J. 2014. Manajemen SDM Dalam Organisasi Publik dan Bisnis. Cetakan Keempat. Bandung. Alfabeta

Tampubolon, Biatna. D. 2007. Analisis Faktor Gaya Kepemimpinan Dan Faktor Etos Kerja Terhadap Kinerja Pegawai Pada Organisasi Yang Telah Menerapkan SNI 19-90012001. Jurnal Standardisasi. Vol. 9 No. 3

Tjiptono. 2006. Manajemen Sumber Daya Manusia Untuk Perusahaan. Jakarta: Raja Grafindo Umar, H. 2008. Metode Penelitian. Jakarta: Bumi Aksara

Wibowo.2015. Perilaku Dalam Organisasi. Jakarta: Rajawali Pers

Winardi. 2002. Motivasi dan Pemotivasian dalam Manajemen. Cetakan kedua. Jakarta: PT Raja Grafindo Persada.

Wirawan. 2009. Evaluasi Kinerja Sumber Daya Manusia. Salemba Empat. Jakarta Wursanto. 2005. Dasar - Dasar Ilmu Organisasi. Yogyakarta : Andi

Yuniarsih dan Suwatno. 2008. Manajemen Sumber Daya Manusia. Bandung: Alfabeta 